\title{
Environmental and genetic determinants of transcriptional plasticity in Chinook salmon
}

\author{
Kyle W. Wellband ${ }^{1} \cdot$ John W. Heath ${ }^{2}$ Daniel D. Heath ${ }^{1,3}$
}

Received: 23 March 2017 / Revised: 30 August 2017 / Accepted: 13 September 2017 / Published online: 10 November 2017

(C) The Genetics Society 2018

\begin{abstract}
Variation in gene transcription is widely believed to be the mechanistic basis of phenotypically plastic traits; however, comparatively little is known about the inheritance patterns of transcriptional variation that would allow us to predict its response to selection. In addition, acclimation to different environmental conditions influences acute transcriptional responses to stress and it is unclear if these effects are heritable. To address these gaps in knowledge, we assayed levels of messenger RNA for 14 candidate genes at rest and in response to a 24-h confinement stress for 72 half-sib families of Chinook salmon reared in two different environments (hatchery and semi-natural stream channel). We observed extensive plasticity for mRNA levels of metabolic and stress response genes and demonstrated that mRNA level plasticity due to rearing environment affects mRNA level plasticity in response to stress. These effects have important implications for natural populations experiencing multiple stressors. We identified genotype-by-environment interactions for mRNA levels that were dominated by maternal effects; however, mRNA level response to challenge also exhibited a non-additive genetic basis. Our results indicate that while plasticity for mRNA levels can evolve, predicting the outcome of selection will be difficult. The inconsistency in genetic architecture among treatment groups suggests there is considerable cryptic genetic variation for gene expression.
\end{abstract}

\section{Introduction}

Phenotypic plasticity has been subject to renewed interest in the past few decades for its role in adaptive responses to changing environmental conditions (Agrawal 2001; Schlichting and Smith 2002; Price et al. 2003; de Jong 2005; Pigliucci 2005; Pfennig et al. 2010). Phenotypic plasticity is broadly represented by two categories of traits: those that result in different development trajectories (nonlabile traits; e.g., metamorphosis) and those that fluctuate

Electronic supplementary material The online version of this article (https://doi.org/10.1038/s41437-017-0009-2) contains supplementary material, which is available to authorized users.

Daniel D. Heath

dheath@uwindsor.ca

1 Great Lakes Institute for Environmental Research, University of Windsor, Windsor, ON N9B 3P4, Canada

2 Yellow Island Aquaculture Ltd., Heriot Bay, BC V0P 1H0, Canada

3 Department of Biological Sciences, University of Windsor, Windsor, ON N9B 3P4, Canada throughout an organism's life (labile traits; e.g., physiological traits). Plasticity can represent an adaptive response to environmental changes if it provides a fitness advantage to that organism in its new or changing environmental context (Ghalambor et al. 2007). Phenotypic plasticity is typically visualized using a reaction norm showing that the shape of the phenotypic response to a particular environmental condition is a property of the genotype (Gotthard and Nylin 1995). There is abundant among-individual variation in the shape of reaction norms for plastic traits (Scheiner 1993), this variation is heritable (Scheiner and Lyman 1989) and the scope for plasticity can indeed evolve through response to selection (Via and Lande 1985; Gotthard and Nylin 1995; Lande 2015). These factors have led to the understanding that the scope for plasticity may be favored by selection and thus plasticity itself considered an adaptation for coping with predictable and frequent environmental change (Gotthard and Nylin 1995).

Alteration of gene expression profiles is believed to be the mechanism underlying many plasticity phenotypes (Schlichting and Smith 2002; Aubin-Horth and Renn 2009). Concentrations of messenger RNA (mRNA) in tissues are widely used as a proxy for gene expression because they are 
the initial rate-limiting stage of gene expression, are easy to quantify, and are a reasonable, if coarse, predictor of protein expression under steady-state conditions (Liu et al. 2016). mRNA levels are themselves phenotypes of an organism that can have important influences on physiology. For example, plastic traits associated with organismal tolerance are mediated by mRNA level changes including rapid responses such as the "heat shock response" (Richter et al. 2010) as well as long-term acclimation processes to different temperatures (e.g., Logan and Somero 2011) and salinities (Lockwood and Somero 2011). In addition to known environmental influences on mRNA profiles, mRNA levels evolve in response to selection (Whitehead and Crawford 2006) and may thus facilitate the rapid evolution of plastic traits.

Despite the important role of mRNA regulation for plastic phenotypes, we lack an understanding of genotypeby-environment interactions for mRNA levels and the genetic architecture of these interactions that would allow us to predict evolution of plastic phenotypes in response to selection. Additionally, genotype-by-environment interactions can reveal cryptic genetic variation when organisms are exposed to uncommon or stressful environments (for reviews see: Ledón-Rettig et al. 2014; Paaby and Rockman 2014). Whether this variation is adaptive or maladaptive can have important consequences for the evolution of populations facing environmental change. Finally, we lack knowledge of a genetic basis for prior environmental conditioning on an organism's plastic mRNA level responses to stressors. Or more generally stated, a genetic basis for plasticity at one time point that affects plasticity at another time point.

Chinook salmon are an excellent model system to investigate the genetic architecture of mRNA levels and the influence of prior environmental conditioning on mRNA profiles. Chinook salmon and related Pacific salmonids exhibit plasticity in mRNA levels as a result of stressful environmental changes (e.g., Aykanat et al. 2011; Aykanat et al. 2012; Jeffries et al. 2014; Tomalty et al. 2015). These mRNA levels have a heritable basis (Aykanat et al. 2012) and there is evidence for the rapid evolution of mRNA level regulation in a closely related species (Oncorhynchus mykiss; Aykanat et al. 2011) suggesting these plastic responses have evolutionary potential. Habitat enrichment (e.g., complex substrate compared to tanks typical of hatchery environments) is known to alter the neural development of Pacific salmonids and has consequences for behavior and growth (Kihslinger and Nevitt 2006). Here we use these features to generate plastic differences between individuals within families due to different rearing habitats and compare their acute mRNA responses to confinement stress in those environments.
To address questions about (1) the effect of plasticity at different time points on mRNA levels, (2) the importance of genotype-by-environment interactions for determining mRNA levels, and (3) the genetic architecture of mRNA levels, we analyzed a large number of half-sibling families of Chinook salmon that were split and reared in two different environments: standard hatchery conditions and a semi-natural stream channel and then subjected to an acute confinement stress. High density forces social interactions, which can be stressful and is a well-known factor contributing to depressed fish health and growth performance in aquaculture (Ewing et al. 1998). Here we used a confinement stress as an efficient means to generate a general stress response to assess the influence of rearing environment (hatchery vs. semi-natural) on organism's ability to alter mRNA levels.

We used a candidate gene approach to investigate genetic architecture and environmental effects on mRNA levels for a variety of core metabolic function genes in the primary tissue controlling metabolic adjustments following stress in fish, the liver (Wiseman et al. 2007). We partitioned variance into environmental and genetic effects and their interactions to characterize plasticity, plasticity for plasticity, genotype-by-environment interaction, and genetic architecture of mRNA levels. Our results provide insight into the quantitative genetic basis of transcription and the influence of environment on resting mRNA levels and response of mRNA levels to stress.

\section{Methods}

\section{Breeding design and rearing environments}

We used a domesticated line of Chinook salmon from Yellow Island Aquaculture Ltd. to perform two fullfactorial breeding crosses using a total of 12 males (sires) and 12 females (dams) crossed in two $6 \times 6$ crosses for a total of 72 half-sib families. Fertilized eggs for each family were divided and incubated in replicated cells of modified incubation trays in a flow-through system fed by well water. When eggs hatched and fish reached the stage of first feeding, individuals from replicated incubation tray cells were pooled together by family and then subdivided into four groups. Two of these groups ( 50 fish each) were placed in separate $200 \mathrm{~L}$ tanks in a standard hatcheryrearing environment (16:8 $\mathrm{h}$ light-dark cycle) to serve as tank replicates representing the hatchery-rearing environment. The other two groups were placed into separate enclosures in a semi-natural stream channel to serve as tank replicates representing the semi-natural rearing environment. 
The enclosures in the semi-natural stream channel were constructed using frame $(120 \times 60 \times 60 \mathrm{~cm})$ and bottom pan made of aluminum from which netting was suspended and secured to all sides. The bottom of these enclosures contained coarse gravel. The enclosures were placed in a semi-natural outdoor stream channel with continuous flow through of well water from the same source as the hatchery. The primary difference between the environmental conditions in the stream channel and the hatchery is the enriched stream channel environment relative to the hatchery; however, exposure to ambient temperature fluctuations and natural light-dark cycles may also be factors. The water level in these enclosures was adjusted prior to adding the fish to allow for a comparable density of fish between the hatchery and channel environments. Due to space constraints, we combined fish from nine families (10 fish per each family) in each replicated enclosure in the semi-natural environment and subsequently performed parentage analysis to assign individual fish back to their family of origin at the end of the experiment (see below). Fish in both environments were fed ad libitum and reared under the two conditions for $\sim 10$ weeks.

\section{Confinement challenge and tissue sampling}

When the fish reached $\sim 2 \mathrm{~g}$ in wet weight, we randomly sampled five fish from each tank in the hatchery and applied a confinement stress that consisted of placing the five fish into a perforated buoyant container $(140 \times 60 \times 75 \mathrm{~mm})$ for $24 \mathrm{~h}$ to simulate a high density of fish $\left(\sim 16 \mathrm{~kg} / \mathrm{m}^{3}\right.$ compared to the rearing density of $\sim 1 \mathrm{~kg} / \mathrm{m}^{3}$ ) in an effort to cause an altered transcriptional state. The same challenge procedure was carried out for fish in the semi-natural enclosures except, due to the nature of the mixed family groups in these enclosures, we randomly netted approximately half of all the fish in the enclosure ( 45 fish) and placed them into the confinement stress in groups of five. The unchallenged fish in both rearing environments served as resting state controls for mRNA levels prior to challenge. For hatcheryreared fish, we collected five fish per tank and for the seminatural enclosures we collected all of the remaining fish in each enclosure. All fish were humanely killed in an overdose solution of clove oil (eugenol, Sigma-Aldrich, Inc., Oakville, ON), their body cavity exposed through dissection and immediately preserved whole in a high salt solution ( $700 \mathrm{~g} / \mathrm{L}$ ammonium sulfate, $25 \mathrm{mM}$ sodium citrate, $20 \mathrm{mM}$ ethylenediaminetetraacetic acid, $\mathrm{pH}$ 5.2). Following $24 \mathrm{~h}$ at $4{ }^{\circ} \mathrm{C}$ to allow the preservative to penetrate all tissues, the samples were frozen and stored at $-20{ }^{\circ} \mathrm{C}$ until further analysis. The statistical design used for mRNA quantification (see below) for this experiment was for two fish per tank replicate, per family, per rearing environment, per challenge treatment for a maximum of 1152 individuals (i.e., 2 fish $\times 2$ tanks $\times 72$ families $\times 2$ rearing environments $\times 2$ challenge treatments).

\section{Parentage analysis}

Because we combined multiple families in each seminatural enclosure, we used microsatellite genotypes to assign parentage for all the fish sampled from the seminatural enclosures. DNA was extracted from a small piece of fin tissue (parents and offspring) using a silica bindingcolumn procedure (Elphinstone et al. 2003). We genotyped all individuals at five microsatellite loci: OtsG68 and OtsG432 (Williamson et al. 2002), Ots208, Ots209, and Ots211 (Greig et al. 2003). PCR reactions consisted of 20 $\mathrm{mM}$ Tris- $\mathrm{HCl} \mathrm{pH} 8.75,10 \mathrm{mM} \mathrm{KCl}, 10 \mathrm{mM}\left(\mathrm{NH}_{4}\right)_{2} \mathrm{SO}_{4}$, $0.1 \%$ Triton $\mathrm{X}-100,0.1 \mathrm{mg} / \mathrm{mL}$ BSA, $200 \mu \mathrm{M}$ each dNTP, $200 \mathrm{nM}$ forward and reverse primers, $2.0 \mathrm{mM} \mathrm{MgSO}_{4}, 0.5$ $\mathrm{U}$ of taq polymerase (Bio Basic Canada Inc., Markham, ON) and $\sim 50 \mathrm{ng}$ of DNA. Conditions for thermal cycling were $95^{\circ} \mathrm{C}$ for $2 \mathrm{~min}, 35$ cycles of $95^{\circ} \mathrm{C}$ for $15 \mathrm{~s}$, locusspecific annealing temperature $\left(52^{\circ} \mathrm{C}-\mathrm{OtsG} 68,56^{\circ}\right.$ C-OtsG432, $58^{\circ} \mathrm{C}$-Ots208, $60^{\circ} \mathrm{C}$-Ots209, Ots211) for 15 $\mathrm{s}$ and $72{ }^{\circ} \mathrm{C}$ for $30 \mathrm{~s}$, followed by $72{ }^{\circ} \mathrm{C}$ for $5 \mathrm{~min}$. Microsatellite PCR products were characterized using a Licor 4300 DNA Analyzer (Licor Biosciences Inc.) and Gene ImagR software (Scanalytics Inc.). Allele sizes were binned by hand based on possible parental allele sizes. The program Cervus v3.0.7 (Kalinowski et al. 2007) was used to perform parentage analysis using the module for known parental pairs. Parentage was assigned using the relaxed $80 \%$ confidence threshold, but preference was given to fish assigned at the $95 \%$ threshold when choosing individuals for gene expression analysis.

\section{Assay selection and design}

Candidate genes (Table 1) were chosen to represent biological functional categories of metabolism, growth, and response to stress that are believed to be important in the early life and development of Chinook salmon. Chinook salmon mRNA sequence for these genes was obtained by mining GenBank and, where necessary, using either rainbow trout $O$. mykiss or Atlantic salmon Salmo salar mRNA sequence. mRNA sequence for these genes was aligned to genomic scaffolds for Atlantic salmon to identify exon-exon boundaries. TaqMan MGB qPCR assays were designed to overlap these boundaries using PrimerExpress 2.0 software (Applied Biosystems Inc., Streetsville, ON). Potential assays were tested and validated by amplifying Chinook salmon complimentary DNA (cDNA) (see below) using SYBR Green-based $\mathrm{qPCR}$ in a $20 \mu \mathrm{L}$ reaction that contained $10 \mu \mathrm{L}$ of SYBRSelect Master Mix, $200 \mathrm{nM}$ each forward and reverse primers, and $\sim 25 \mathrm{ng}$ of cDNA reverse 
Table 1 Quantitative real-time PCR assays for measuring standing mRNA concentrations for Chinook salmon genes including codes and full gene names, NCBI GenBank accession numbers for sequences used to design the assays, the primer $(F$ forward, $R$ reverse) and probe $(P)$ sequences, and the empirically estimated PCR efficiency

\begin{tabular}{|c|c|c|c|c|}
\hline & Gene name & GenBank accession & Primer/probe sequences & PCR efficiency \\
\hline \multicolumn{5}{|c|}{ Reference genes } \\
\hline$B A C T I N$ & $\beta$-actin & FJ890357.1 & $\begin{array}{l}\text { F: GACCCAGATCATGTTTGAGACCTT } \\
\text { R: TCCATGACGATACCGGTGGTA } \\
\text { P: CAGGCCGTGTTGTC }\end{array}$ & 2.013 \\
\hline$E F 1 A$ & Elongation factor $1 \alpha$ & AF498320.1 & $\begin{array}{l}\text { F: AATACCCTCCTCTTGGTCGTTTC } \\
\text { R: CTTGTCGACGGCCTTGATG } \\
\text { P: TGCGTGACATGAGGC }\end{array}$ & 1.983 \\
\hline \multicolumn{5}{|c|}{ Growth genes } \\
\hline GHR & Growth hormone receptor & NM_001124731.1 & $\begin{array}{l}\text { F: CCCCACTAAAGAGTCCCGATT } \\
\text { R: CTAAACCCAAGGCAGCAAAGA } \\
\text { P: CCAGTTACTGTCCTGCTT }\end{array}$ & 1.927 \\
\hline$I G F B P 2 B$ & Insulin-like growth factor binding protein $2 \mathrm{~b}$ & HM358881.1 & $\begin{array}{l}\text { F: CAACTGTCCCGAGGAACCTAAG } \\
\text { R: CTCCAGCTCCTGTGCACAAG } \\
\text { P: CCCAGCAGCCCATGA }\end{array}$ & 1.780 \\
\hline$I G F I$ & Insulin-like growth factor 1 & U14536.1 & $\begin{array}{l}\text { F: ATTTCAGTAAACCAACGGGCTATG } \\
\text { R: CGTCCACAATACCACGGTTATG } \\
\text { P: CCAGTTCACGACGGTC }\end{array}$ & 1.873 \\
\hline$T H R-B$ & Thyroid hormone receptor $\beta$ & AB303988.1 & $\begin{array}{l}\text { F: GCTCTGCTACAGGCCGTCAT } \\
\text { R: GTTCAAAGGCCAGAAGGAACTC } \\
\text { P: TCCTCCGACCGTCCG }\end{array}$ & 1.876 \\
\hline \multicolumn{5}{|c|}{ Immune genes } \\
\hline$C A L$ & Calmodulin & ВТ074280.1 & $\begin{array}{l}\text { F: CAGACAGCGAGGAGGAGATCA } \\
\text { R: TAACCGTTCCCATCCTTGTCA } \\
\text { P: AGAAGCGTTCCGTGTCT }\end{array}$ & 1.807 \\
\hline MHCIIB & Major histocompatibility complex class 2 & U34718.1 & $\begin{array}{l}\text { F: GCCATACTGGACAAGACAGTTGAG } \\
\text { R: TCATAGGCGCTGCACATCAG } \\
\text { P: CCCATGTCAGACTGAG }\end{array}$ & 1.911 \\
\hline$N K E F$ & Natural killer enhancing factor & AF250193.1 & $\begin{array}{l}\text { F: TGAGGTCATTGGTGCCTCTGT } \\
\text { R: GAGGTGTGTTGGTCCAAGCA } \\
\text { P: ATTCCCACTTCTGCCATC }\end{array}$ & 1.991 \\
\hline \multicolumn{5}{|c|}{ Metabolic genes } \\
\hline PEPCK & Phosphoenolpyruvate carboxykinase & AF246149.1 & $\begin{array}{l}\text { F: ACAAAGGCAAGGTTATCATGCA } \\
\text { R: ACCGAAGTTGTAGCCGAAGAAG } \\
\text { P: ACCCCTTCGCCATGC }\end{array}$ & 1.940 \\
\hline $\mathrm{COI}$ & Cytochrome $c$ oxidase subunit 1 & KP720599.1 & $\begin{array}{l}\text { F: GGCAGCAGGCATTACTATGTTACTC } \\
\text { R: GCCTGCCGGGTCAAAGA } \\
\text { P: CGGACCGAAATCTA }\end{array}$ & 1.911 \\
\hline$F A S$ & Fatty acid synthase & XM_014179800.1 & $\begin{array}{l}\text { F: CCAGGTCTGTACGGTCTTCCA } \\
\text { R: CGAACCGGCTGATGTCCTT } \\
\text { P: AGAGGAACGGCAAGCT }\end{array}$ & 1.840 \\
\hline CYP1A & Cytochrome p450 1A & M21310.1 & $\begin{array}{l}\text { F: TCTTCCTTCCTGCCGTTCAC } \\
\text { R: GAAGTAGCCATTGAGGGATGTGT } \\
\text { P: CCACACTGCACGATC }\end{array}$ & 2.339 \\
\hline$C P T 1$ & Carnitine palmytol transferase 1 & AJ620357.1 & $\begin{array}{l}\text { F: GAAGGGCCTGATCAAAAAGTGT } \\
\text { R: TCCCCTTGTCCCTGAAGTGA }\end{array}$ & 1.886 \\
\hline
\end{tabular}


Table 1 (continued)

\begin{tabular}{|c|c|c|c|c|}
\hline & Gene name & GenBank accession & Primer/probe sequences & PCR efficiency \\
\hline & & & P: CTTCATCCAGATCGC & \\
\hline \multicolumn{5}{|c|}{ Stress genes } \\
\hline \multirow[t]{3}{*}{$G R 2$} & Glucocorticoid receptor 2 & AY495372.1 & F: AGCACCGTGCCAAAAGATG & 1.756 \\
\hline & & & R: GCCTTCCCCAACTCCTTGA & \\
\hline & & & P: CTCATCAAACACTGCCTG & \\
\hline \multirow[t]{3}{*}{ HSP70 } & Heat shock protein 70 & U35064.1 & F: TCAACGATCAGGTCGTGCAA & 1.910 \\
\hline & & & R: CGTCGCTGACCACCTTGAA & \\
\hline & & & P: CCGACATGAAGCACTG & \\
\hline \multirow[t]{3}{*}{ META } & Metallothionein A & DQ139342.1 & F: GCTCCAAACTGGATCTTGCAA & 1.889 \\
\hline & & & R: TGGTGCATGCGCAGTTG & \\
\hline & & & P: TGCGGTGGATCCTG & \\
\hline
\end{tabular}

Note that gene function category is based on primary gene function reported in the literature; however, most genes have multiple functions

transcribed from total RNA. Melt-curve analysis and gel electrophoresis were used to verify the lack of primer dimer and the expected size of the amplicon.

\section{RNA extraction, reverse transcription, and quantitative real-time PCR}

Total RNA was extracted from liver tissue using RNAzol (Sigma-Aldrich, Inc., Oakville, ON) following the manufacturers recommended protocol. RNA concentration and purity were assessed using a NanoVue spectrophotometer (GE Life Sciences Inc., Mississauga, ON) and integrity of RNA was assessed using electrophoresis. Only RNA samples with intact 28S and 18S rRNA bands and A260/A280 ratios above 1.9 were used for gene expression analysis. Total RNA (500 ng) was treated with DNase I (New England Biolabs Ltd., Whitby, ON) following the manufacturers recommendations and then reverse transcribed using a High-Capacity cDNA Reverse Transcription Kit (Thermo Fisher Scientific, Inc., Streetsville, ON). cDNA was diluted by combining 4.8 with $5.2 \mu \mathrm{L}$ of $\mathrm{ddH}_{2} \mathrm{O}$. Diluted cDNA $(2.5 \mu \mathrm{L})$ was combined with an equal amount of TaqMan OpenArray Real-Time Master Mix (Thermo Fisher Scientific, Inc., Streetsville, ON), loaded onto custom designed OpenArray plates and run using the default settings for the OpenArray technology on a QuantStudio 12K Flex Real-Time PCR system (Thermo Fisher Scientific, Inc., Streetsville, ON). Assays that failed to amplify were removed from the data set and $C_{\mathrm{RT}}$ (fractional PCR cycle at which fluorescence reached threshold for quantification) values for valid assays were obtained from the QuantStudio software. Due the stochastic nature of conducting nano volume PCRs, we subsequently excluded any assays that amplified in more than 30 cycles $\left(C_{\mathrm{RT}}>30\right)$ as these represent $\sim 1$ copy of DNA present in the $33 \mathrm{~nL}$ assay volume and variation beyond this threshold reflects technically induced stochasticity and not biological variation.

We calculated amplification efficiency empirically for each gene using the program LinRegPCR (Ramakers et al. 2003). This program estimated the amplification efficiency from the slope of the line of best fit for the linear phase of amplification on the log-transformed data. For computational reasons, we only used a subset of the data (144 individuals) for these calculations. Given PCR efficiency is a property of the amplicon (Karlen et al. 2007) and the method we used averages efficiency over individuals for each loci, the use of a subset of the data represents a reasonable tradeoff between computational speed and confidence in the parameter of interest (PCR amplification efficiency).

The $C_{\mathrm{RT}}$ for technical replicate assays within an individual were averaged for each gene and we calculated starting concentrations of DNA for each gene in each individual following the methodology of Tuomi et al. (2010) to correct for PCR efficiency and the accumulation of fluorescence due to the use of TaqMan probes. We calculated a normalization factor for each individual by taking the geometric mean of the expression of two reference genes $(\beta$-actin and $E F-1 \alpha$ ) for each individual. Stability of expression of these genes across all samples was assessed using the geNorm algorithm (Vandesompele et al. 2002) as implemented in the NormqPCR v1.20.0 package (Perkins et al. 2012) in $\mathrm{R}$ v3.1.3 ( $\mathrm{R}$ Core Team 2016). The two reference genes represented the most stably expressed and the fourth most stably expressed genes in the data set (results not shown) confirming their appropriateness as reference genes for organisms in our study. A relative quantification value for each gene was then produced for all genes of interest by expressing them relative to the normalization factor for each individual. This method is analogous to producing a $\Delta C_{\mathrm{T}}$. 


\section{Plasticity of mRNA levels}

For this experiment, we were interested in the influence of rearing environment and confinement stress (plasticity) on mRNA levels, genotype-by-environment interactions for mRNA levels and the genetic architecture of both mRNA levels as well as the genotype-by-environment interactions. We began by fitting a maximal (all factors included) linear mixed-effect model. We fit the model to log-transformed relative transcription of each gene using restricted maximum likelihood as implemented in the "lme4" v1.1-12 package in $\mathrm{R}$ ( $\mathrm{R}$ Core Team 2016). The model had fixed effects of rearing environment, confinement challenge, and their interaction and random effects of sire, dam, and all two-, three- and four-way interactions of sire, dam, rearing environment, and confinement challenge as well as a random effect for replicate tanks/enclosures. Statistical significance of the fixed (environmental) effects was determined using approximate F-tests with models fit with maximum likelihood and degrees of freedom estimated based on the Kenward-Rogers approach (Kenward and Roger 1997) as implemented in the pbkrtest v0.4-6 package in R (Halekoh and Højsgaard 2014).

The results of this model confirmed that most of our genes exhibited a response to confinement stress or an interaction between confinement stress and rearing environment, so we also calculated the mRNA level response to confinement challenge for all genes by normalizing to the control (resting) mRNA level. We did this by subtracting the average resting mRNA level for a gene within each family within each environment from the individual mRNA levels for challenged fish in that family in that environment. This metric accounts for differences among families and rearing environments in the resting mRNA levels and thus represents a scope for response to stimulus (in this case the stress response). The ability of an organism to alter biological function may not be a function of the amount of mRNA for a gene but the degree to which it can alter the amount of mRNA for that gene from one condition to another. For this reason, we consider both post-stress mRNA levels as well as our normalized mRNA level response metric in our analyses.

\section{Genotype-by-environment interaction}

To identify genotype-by-rearing-environment interactions for both resting mRNA levels and mRNA level response, we used linear mixed effects models that contained a fixed effect of environment, a random effect representing the fullsib families (completely independent families (diagonal of the two $6 \times 6$ full-factorial crosses), $N=12$ ), and a random effect of the interaction between family and environment. We used the full-sib families as our proxy for genotype because they satisfy the assumption of independence from one another (not met by the remaining half-sib families who share a parent) and most closely represent a single genotype in our study. We tested the significance of random effect terms in the model using likelihood ratio tests, where the term of interest was dropped from the model and the change in the log-likelihood of the reduced model compared to the full model was compared to a $\chi^{2}$ distribution with one degree of freedom. To test the statistical significance of the fixed effect of environment, we used approximate F-tests on models fit with maximum likelihood with degrees of freedom estimated based on the Kenward-Rogers approach as described above.

\section{Genetic architecture of transcription}

To investigate the nature of genetic architecture-environment interactions, we used the maximal model from above where we tested the significance of the random effect terms in the model using likelihood ratio tests by dropping the term of interest from the model and the change in the log-likelihood of the reduced model compared to the full model was compared to a $\chi^{2}$ distribution with one degree of freedom. In addition, we used a second linear mixed-effect model fit to the change in mRNA level (response) to confinement challenge. The model was fit to logtransformed relative mRNA levels of each gene as described above with a fixed effect for rearing environment and random effect terms for sire, dam, sire $\times$ dam interaction, sire $\times$ environment interaction, dam $\times$ environment interaction, the three-way interaction between sire $\times$ dam $\times$ environment, and replicate tanks/enclosures. We tested the significance of random effect terms as described above.

Genes exhibited significant interactions between both types of environments (rearing and confinement), suggesting that the genetic architecture of transcription depends on the environment. Thus we then analyzed the genetic architecture of mRNA levels for each rearing environment and confinement treatment combination in four separate models. We used random effect models to partition variance in mRNA levels due to sire, dam, sire $\times$ dam interaction as well as replicate tanks/enclosures. The significance of each term in the model was tested using likelihood ratio tests. We used the variance components provided by these models to calculate, in each environment separately, additive genetic variance $\left(V_{\mathrm{A}}: 4 \times\right.$ sire variance), maternal effects ( $V_{\mathrm{M}}$ : dam variance-sire variance), and nonadditive genetic variance $\left(V_{\mathrm{NA}}: 4 \times\right.$ sire:dam interaction variance) for a full-factorial breeding cross (Lynch and Walsh 1998) as well as the narrow-sense heritability $\left(V_{\mathrm{A}} /\right.$ total phenotypic variance). 

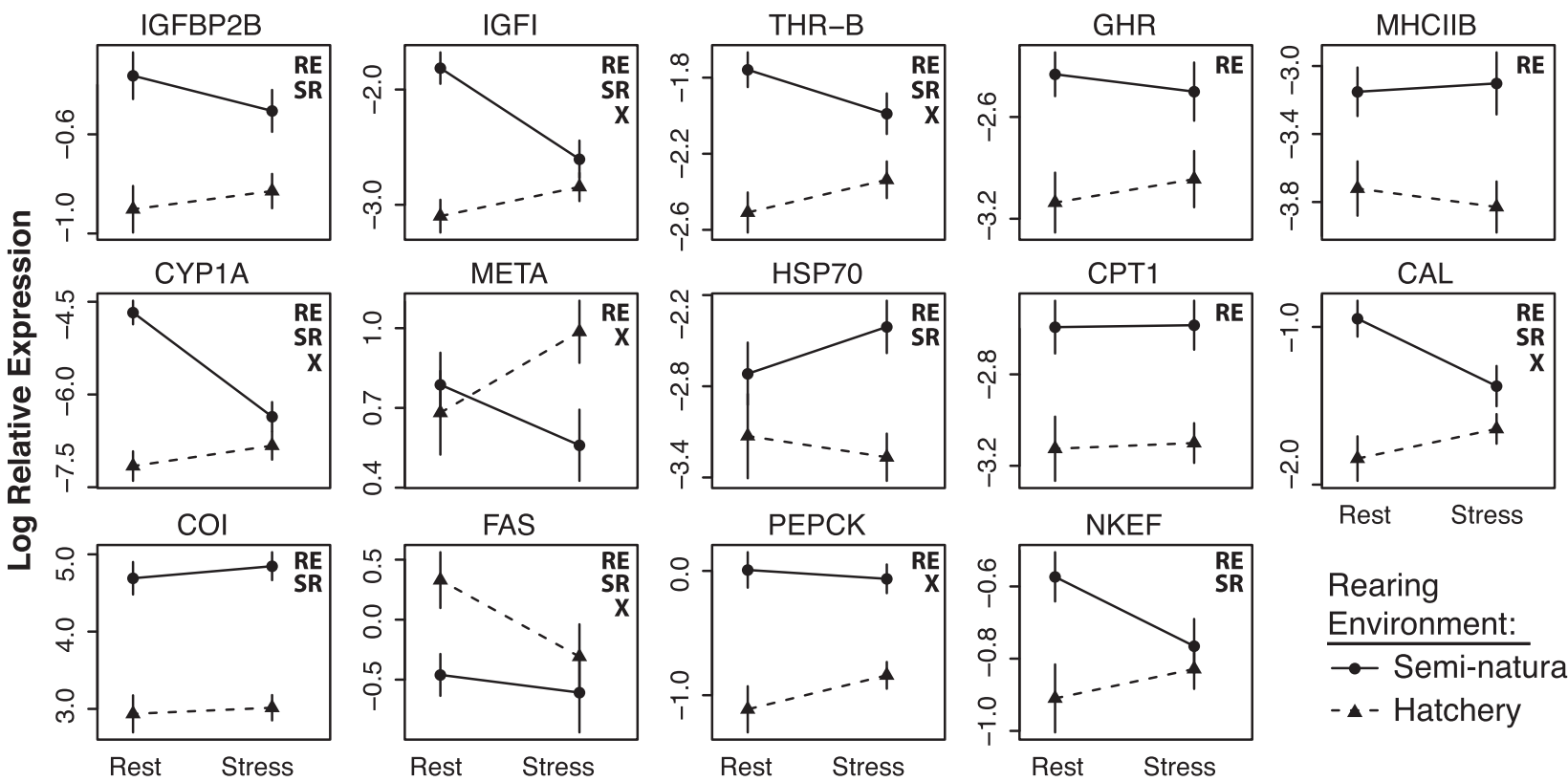

Fig. 1 Plasticity of liver mRNA levels for 14 genes in 72 half-sib Chinook salmon families at two temporal scales: (1) rearing environment (semi-natural and hatchery) and (2) stress response to an acute confinement stress for $24 \mathrm{~h}$ (rest and stress). Points (mean $\pm 2 \mathrm{SE}$ ) represent the estimated coefficient from the linear model and the

\section{Results}

We obtained quantitative real-time PCR data for 15 candidate genes involved in metabolism, growth, stress response, and two reference genes (Table 1) for 1041 Chinook salmon individuals. There were two families in the hatchery environment that we were unable to perform the confinement challenge on due to low survival. Otherwise data were obtained for a minimum of 68/72 families in both treatments in the hatchery environment. While the data set for the seminatural channel had more missing families, all but one gene in the control treatment and six genes in the confinement challenge for channel acclimated fish were represented by $>65 / 72$ families. The greater level of missing data was related to a reduced number of fish available for the confinement challenge and a loss of fish due to low confidence with which parentage could be assigned for these fish. The different numbers of families available across genes corresponds to situations where the sole representative of a family (for the reasons just described) may also be missing data for a particular gene. One gene (GR2) was missing data for $\sim 45 \%$ of individuals and thus was not analyzed. All other genes had data for more than $75 \%$ of individuals.

\section{Plasticity of mRNA levels}

All genes demonstrated statistically significantly different mRNA levels between rearing environments (Fig. 1). We statistical significance of main effects ( $R E$ rearing environment, $S R$ stress response) and interactions (X) are indicated in each plot as determined using a linear mixed effects model with approximate Ftests using the Kenward-Rogers approach to estimate degrees of freedom

also identified significant mRNA level changes for 9 of the 14 genes in response to confinement stress, and half of the genes (7/14) also exhibited a significant interaction for mRNA levels between rearing environment and confinement stress (Fig. 1; Table S1). These results indicate extensive plasticity for mRNA levels at multiple timescales and that plasticity at one timescale (rearing environment) effects plasticity at other timescales (response to stress).

\section{Genotype-by-environment interaction}

Among the full-sib families, we identified significant genotype-by-environment interactions for mRNA levels of three genes at rest and three genes in response to confinement challenge for the full-sib families (Figs. 2, 3). These results are further corroborated by the genetic variance-byenvironment interactions from the maximal model, where mRNA levels were different for three genes in dam $\times$ rearing environment interactions, one gene in a dam $\times$ confinement challenge interaction, and three genes in dam $\times$ rearing environment $\times$ confinement challenge interactions (Table S1). In addition, mRNA level response to confinement challenge of 12 genes exhibited significant sire $\times$ dam $\times$ environment interactions (Table S2). These both represent genetic architecture-environment interactions and indicate that environment influences genetic architecture of mRNA levels at multiple levels. 

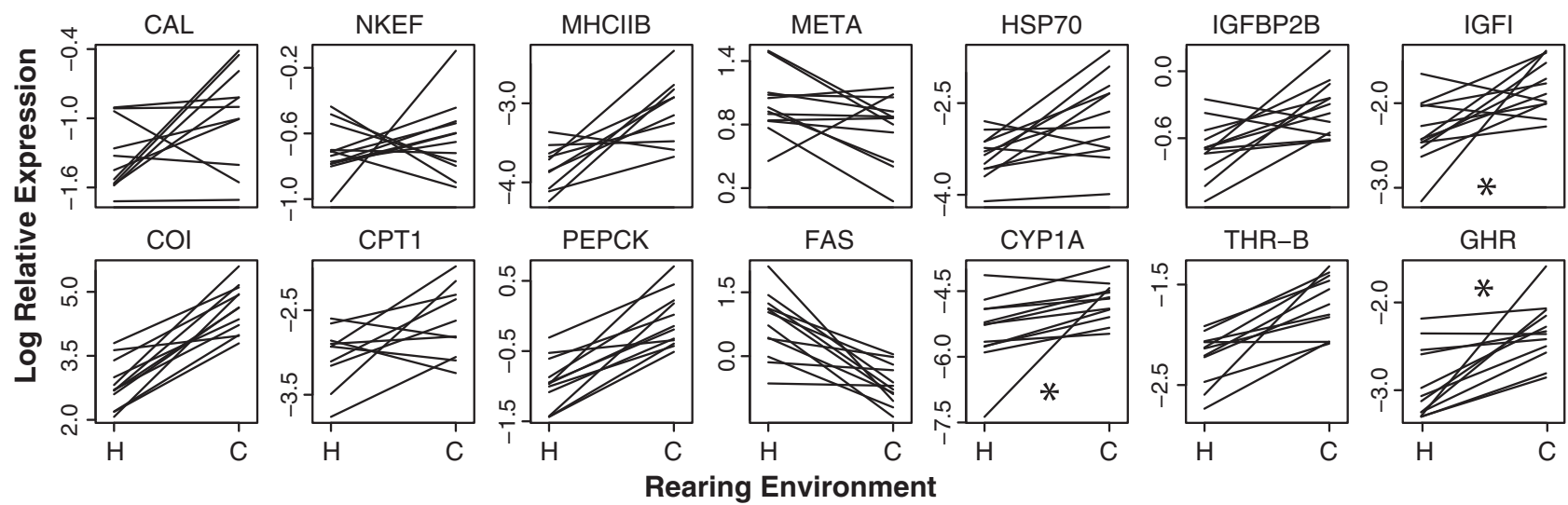

Fig. 2 Reaction norms for the mean within-family resting mRNA levels of 14 genes in the liver of Chinook salmon reared in hatchery $(\mathrm{H})$ and semi-natural environments $(\mathrm{C})$. Each line represents a separate full-sib family (no parents are shared among families and thus all

\section{Genetic architecture of mRNA levels}

To obtain environment-specific estimates of the genetic architecture of mRNA levels, we separated the data and characterized genetic architecture in each combination of rearing environment and confinement challenge. There was very little statistically significant additive genetic variance for either resting mRNA levels or mRNA level response to confinement (Fig. 4; Table S3). Estimates of the narrow-sense heritability $\left(h^{2}\right)$ ranged from 0 to 0.81 , while the majority of estimates were $<0.2$ (Fig. 4; Table S3). The estimates of additive genetic variance for both mRNA level measures were uncorrelated between environments (Fig. 5) and tended to represent a higher proportion of variation in the hatchery environment with the exception of stress in the channel environment (Figs. 5, 6). A similar pattern was observed for both dam variance and non-additive genetic variance and was the result of a consistently higher level of phenotypic variance in the channel environment. Due to the potential for differences in power due to the number of families present in different treatment groups, we also conducted these analyses with only the families shared among all groups. Variance components were highly correlated with the results we presented above $\left(R^{2}\right.$ range: $\left.0.97-0.99\right)$ and the slopes did not differ from one indicating minimal bias in our estimates.

\section{Discussion}

We demonstrated significant environmental effects on mRNA levels in Chinook salmon at two different temporal scales: long-term rearing environment effects and shortterm response to confinement stress. We also identified widespread interactions between rearing environment and response to confinement stress in Chinook salmon. Our families presented are independent, see text for details). Asterisks indicate statistically significant genotype-by-environment interactions for resting mRNA levels (crossing of reaction norms). Confidence intervals for family means have been omitted for clarity

results reflect phenotypic plasticity for mRNA levels and the interactions of plasticity at different temporal scales reflects environmentally context-dependent plasticity in mRNA levels. While not always characterized in the same context, there is an emerging body of literature highlighting the importance of prior environmental exposure to stress responses mediated by altered mRNA levels. For example, differential thermal acclimation has been shown to affect mRNA-mediated immune responses of cod (Hori et al. 2012) and acute mRNA responses to temperature challenge (e.g., Dietz and Somero 1992; Logan and Somero 2011; Komoroske et al. 2015). Our results are consistent with this existing work and demonstrate that something seemingly as benign as subtle alterations in rearing environment can have profound effects on mRNA responses to stress. Habitat alterations are a well-documented threat to salmon and while we have not demonstrated the rearing environment differences affected the fitness of our fish, it is easy to imagine that habitat alterations may impair the ability of fish to respond to other stressors.

mRNA level responses to environmental stressors are associated with organisms' ability to alter biological functions to maintain homeostasis in the face of rapid environmental change (Kassahn et al. 2009). Increased densities (simulated by our confinement challenge) in salmonid aquaculture are known to have a negative influence on growth (Ewing et al. 1998). The physiological stress responses to increased density may be transient (Wedemeyer 1976), but their effects on mRNA levels and control of metabolic processes underlying long-term changes in performance are mediated through mRNA level alterations in the liver (Mommsen et al. 1999). The mRNA level responses we observed are consistent with mRNA level responses to stress in the liver (Wiseman et al. 2007) and reflected reductions in energy allocation to growth (down 

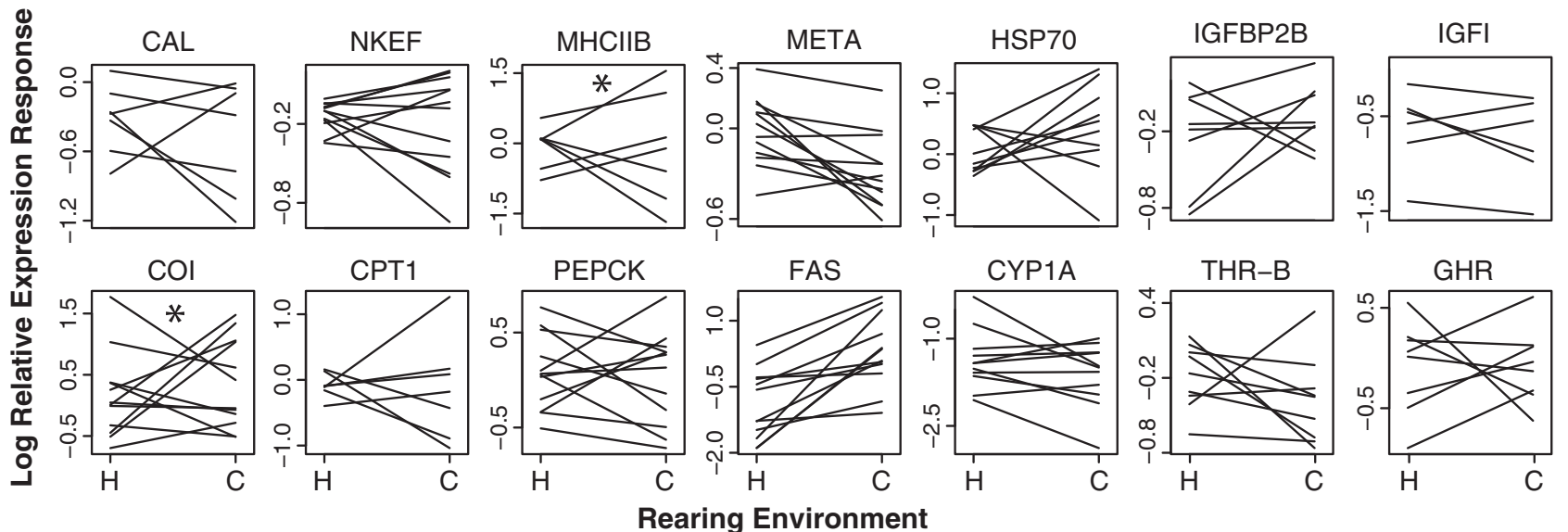

Fig. 3 Reaction norms for the mean within-family mRNA levels in response to $24 \mathrm{~h}$ of confinement stress for 14 genes in the liver of Chinook salmon reared in hatchery $(\mathrm{H})$ and semi-natural environments (C). Each line represents a separate full-sib family (no parents are shared among families and thus all families presented are independent, see text for details). Response was calculated as the difference between

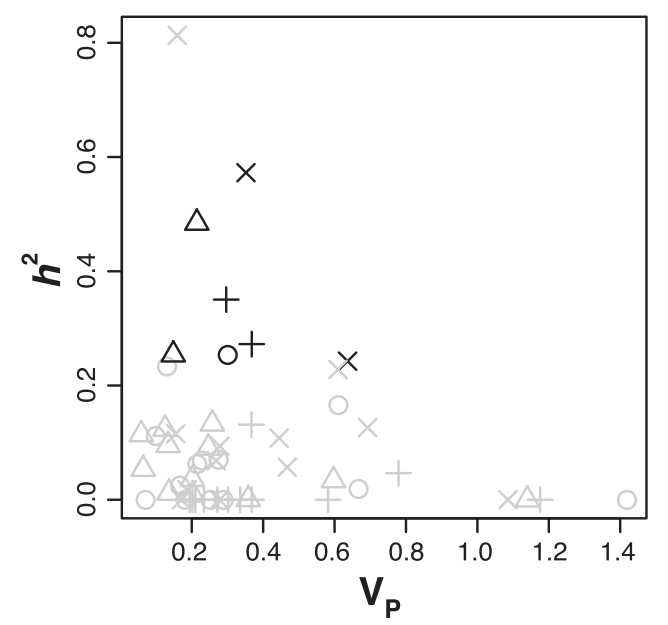

Fig. 4 Narrow-sense heritability $\left(h^{2}\right)$ for mRNA levels as a function of the total phenotypic variance $\left(V_{\mathrm{P}}\right)$ for 14 genes in the liver of Chinook salmon reared in hatchery and semi-natural channel environments at rest (circles and + , respectively) and following a $24 \mathrm{~h}$ confinement stress (triangles and $\times$, respectively). Statistically significant estimates indicated by black symbols

regulation of $I G F I, I G F B P 2 b$, and $T H R-B)$ and a switch from energy storage (downregulation of $F A S$ ) to mobilization of energy through upregulation of gluconeogenesis $(P E P C K)$. We also identified signatures of the cellular stress response with the upregulation of GR2 and HSP70. These mRNA level responses are consistent with expected adaptive responses to recover homeostatic function and the metabolic rearrangements necessary to meet changing energy demands (Wendelaar Bonga 1997; Kassahn et al. 2009). An unresolved question is how impaired mRNA responses to stress due to prior exposure to different environments might affect the survival and fitness of mean mRNA levels under control and confinement challenge conditions for each family in each acclimation environment. Asterisks indicate statistically significant genotype-by-environment interactions (crossing of reaction norms) for mRNA level response to the confinement challenge. Confidence intervals for family means have been omitted for clarity

differentially reared individuals. Given the specter of multiple stressors facing salmonid populations (e.g., climate change, habitat alterations, human exploitation, pollution), it is increasingly relevant to understand the interacting effects of environmental factors on the ability of organisms to maintain homeostasis. While our experiment is not a prefect proxy for plasticity induced by alterations of natural habitats, the use of a domestic strain of salmon that has been under selection for hatchery conditions for more than five generations should approximate situations involving at least mild levels of habitat alterations.

Genotype-by-environment interactions are a common occurrence for plastic phenotypes (Scheiner 1993); however, few studies have measured the quantitative genetic basis of these interactions. We identified genotype-byenvironment effects primarily as dam-by-environment interactions for resting mRNA levels and both dam-byenvironment and non-additive-by-environment interactions for mRNA level response to confinement stress. This was partly driven by larger magnitudes of dam and non-additive variance components in the hatchery as a result of the lower phenotypic variance for transcription; however, even controlling for these effects did not change the overall patterns of interactions among environments. The lack of additive genetic-by-environment variance suggests plasticity for mRNA levels will not evolve in a predictable manner and implies there may be considerable cryptic genetic variation for expression of these genes (Paaby and Rockman 2014). Indeed, recent studies of environmentally relevant gene expression in fish have revealed the role of non-adaptive plasticity in exposing cryptic variation and driving evolution of gene expression (Dayan et al. 2015; Ghalambor et al. 2015). Expression quantitative trait loci (eQTL) approaches 

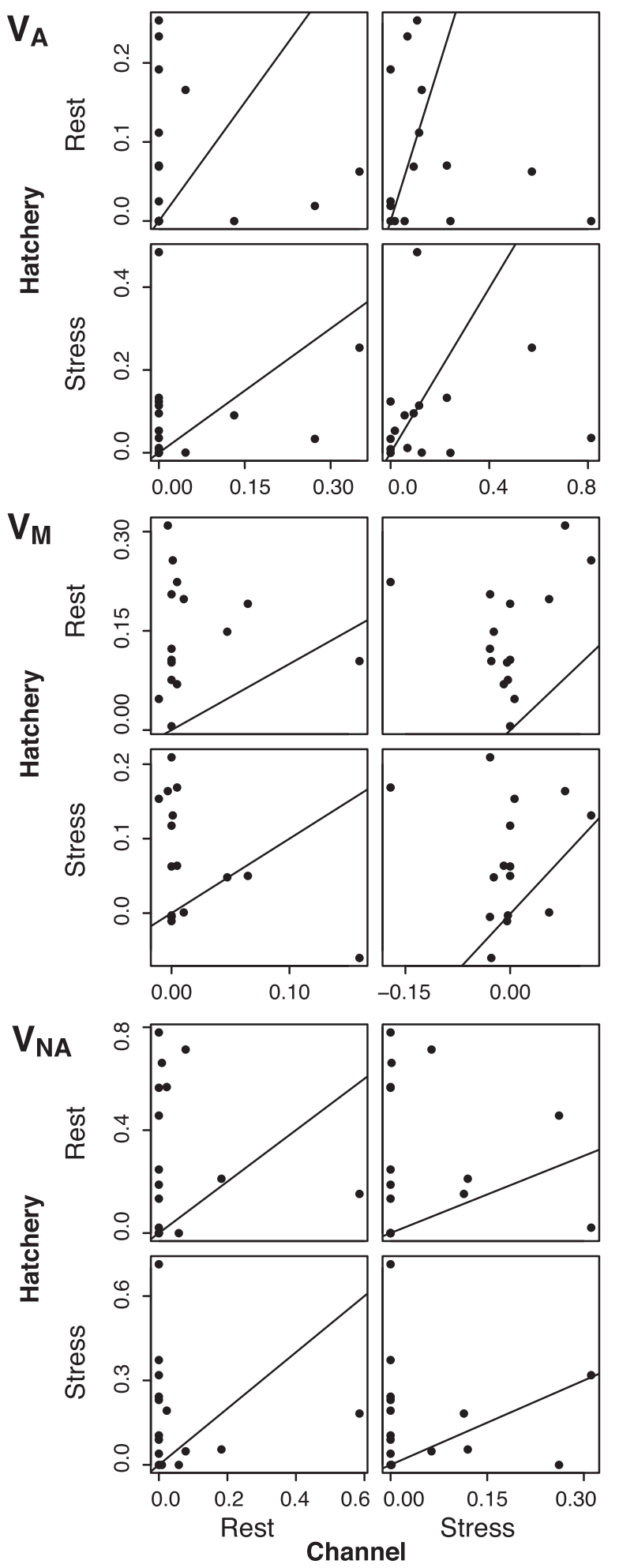

Fig. 5 Comparison of the additive $\left(V_{\mathrm{A}}\right)$, non-additive $\left(V_{\mathrm{NA}}\right)$ genetic variance, and maternal $\left(V_{\mathrm{M}}\right)$ effects estimated in hatchery and seminatural channel environments for resting mRNA levels and mRNA level response to confinement stress. Estimates are based on up to 72 Chinook salmon families. Solid lines represent the one to one relationship expected if environment did not play a role in the genetic architecture of mRNA levels

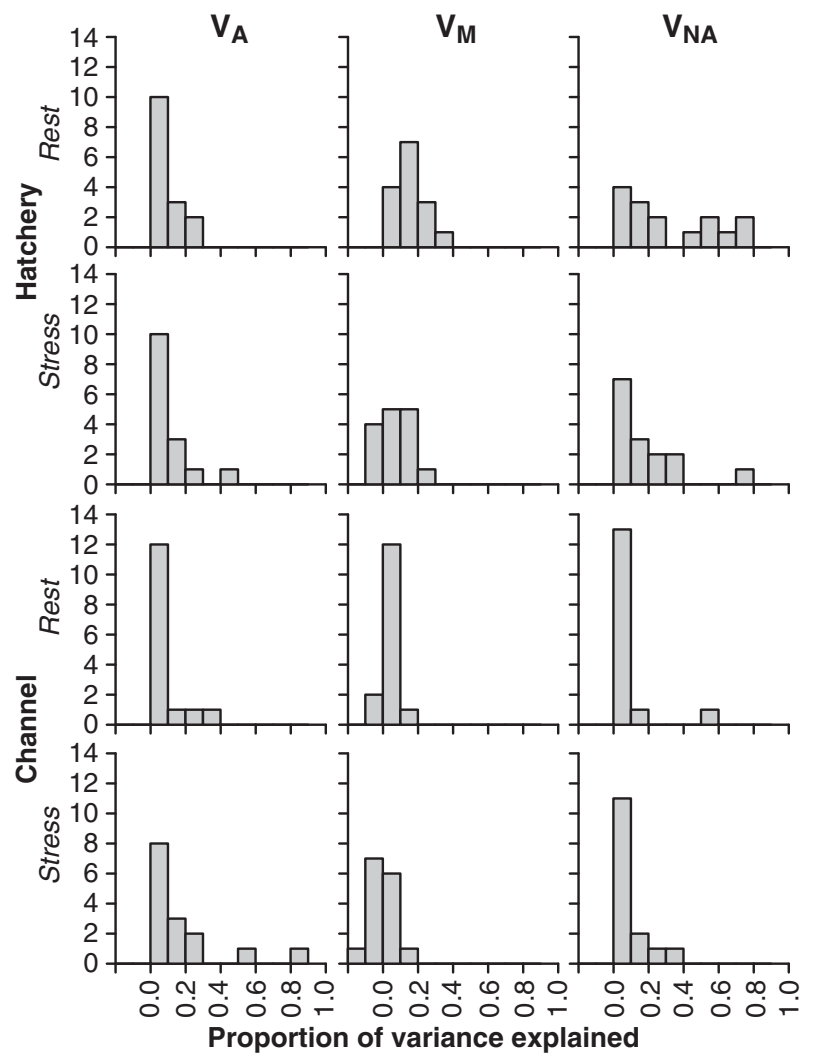

Fig. 6 Distribution of proportion of total phenotypic variance explained by additive genetic $\left(V_{\mathrm{A}}\right)$, maternal $\left(V_{\mathrm{M}}\right)$, and non-additive genetic $\left(V_{\mathrm{NA}}\right)$ components for mRNA levels of 14 genes from Chinook salmon reared in hatchery and semi-natural channel environments at rest and following $24 \mathrm{~h}$ of an acute confinement stress. The values presented for $V_{\mathrm{A}}$ are equivalent to the narrow-sense heritability $\left(h^{2}\right)$ for mRNA levels

hold promise for identifying the specific variants involved in regulating transcription of genes (Gibson and Weir 2005) and provide a means for better characterizing both the genetic architecture of mRNA profiles and genotype-byenvironment interactions for mRNA levels.

Our ability to predict evolution of gene transcription in response to environmental change depends not only on the environmental parameters but also the genetic architecture of mRNA levels. Compared to the widespread environmental effects, we observed only a small number of genes with significant additive genetic variance for mRNA levels at rest or in response to confinement challenge. Our results stand in contrast to some studies that have demonstrated extensive additive inheritance for transcription (Kim and Gibson 2010; Leder et al. 2015), as we only detected significant additive variance for one gene in the hatchery and two in the semi-natural channel for resting transcription, and one gene in the hatchery for mRNA level response. The narrow-sense heritabilities for these genes were comparable to estimates for genome-wide heritability of transcription for stickleback (Leder et al. 2015) and cytokine 
transcription in Chinook salmon (Aykanat et al. 2012). The limited additive genetic variance in transcription may reflect evolutionarily canalized mRNA level responses to environments. The core metabolic genes we studied are critical for survival and it may be that additive genetic variation in these traits has been reduced or lost through past selection on transcription of these genes (Lynch and Walsh 1998). While the use of a candidate gene approach allowed us to test specific genes known to be involved in stress responses, this approach limits our ability to generalize a discussion of the quantitative genetics of mRNA levels across the whole transcriptome. Nevertheless, a lack of additive genetic variation for mRNA levels will limit the predictability of their evolutionary response to selection.

Similar to Aykanat et al. (2012), we found significant maternal effects for both resting mRNA levels (12/15 genes in the hatchery and one gene in the semi-natural channel) and mRNA level response to a challenge $(6 / 15$ genes in the hatchery but none in the semi-natural channel). These results are consistent with the extensive evidence for maternal effects in early life history traits of Chinook salmon (Evans et al. 2010; Aykanat et al. 2012). It is interesting that maternal effects are important in one environment but not in the other. These results hint at the important role that maternal effects may play in facilitating adaptive responses to different environments (Mousseau and Fox 1998). Context-dependent maternal effects (e.g., Plaistow and Benton 2009), where certain mothers perform better in certain environments but not all, suggest that maternal contributions to phenotypic variance may be a mechanism supporting the extensive local adaption observed in salmonids (Taylor 1991; Aykanat et al. 2012). The architecture (maternal genetic vs. maternal environment) underlying these maternal effects is unclear; however, epigenetic modifications (e.g., DNA methylation) have been documented in mediating maternal effects in mammals (Kappeler and Meaney 2010) and are increasingly implicated in important ecological divergence among populations of fish (Artemov et al. 2017). DNA methylation directly influences the expression of mRNA and appears to be a promising direction for future research to understand plasticity and divergence of mRNA phenotypes.

Our analyses revealed significant non-additive genetic variation for mRNA level response to confinement stress. The non-additive variation we detected reflects the complex genomic mechanisms that underlie mRNA level variation and likely reflects primarily dominance and epistatic effects (Lynch and Walsh 1998). Epistasis has been frequently suggested to explain the extensive non-additive variation observed for transcriptional traits (Gibson and Weir 2005; Gilad et al. 2008) and is a logical assumption given the complex interactions involved in regulation of transcription (Wittkopp and Kalay 2012). Widespread dominance effects have also been demonstrated for genome-wide transcription in stickleback (Leder et al. 2015). Non-additive genetic effects would allow transcription to evolve in response to selection (e.g., Bourguet 1999); however, predicting the response may not be possible. It is important to note that the response metric we calculated represents the family mean mRNA levels at rest subtracted from the stressed fish data. Thus any error in estimating family means at rest will be propagated into this response data. Some care should be taken interpreting these results, as it is possible we have overestimated the importance of the non-additive genetic effects in this analysis. In spite of this, the magnitude of non-additive effects estimated on measured mRNA across the four treatment groups (Fig. 4) indicates differences in the importance of non-additive effects in different environments supporting the non-additive-by-rearing-environment interactions we observed for the mRNA response metric.

We have demonstrated plasticity for mRNA levels and an interaction among mRNA level plasticity at different temporal scales (long-term rearing environment and shortterm stress response) for Chinook salmon rearing in hatchery and semi-natural environments at rest and in response to a confinement stress. Genotype-by-environment interactions for mRNA levels are caused by both maternal and non-additive genetic variation (dominance and epistasis effects). Our results confirm a heritable basis of mRNA level plasticity; however, they highlight the complex inheritance of mRNA level traits. Linking the consequences of plasticity for plasticity in mRNA levels to measures of fitness and knowledge of the genetic architecture of genotype-by-environment interactions for mRNA levels will improve our ability to predict evolutionary response to environmental change and the impact of multiple stressors on important transcriptional responses to stress.

\section{Data accessibility}

The raw data and $\mathrm{R}$ scripts used to analyze the data are available from the Dryad Digital Repository: http://dx.doi. org/10.5061/dryad.p148m.

Acknowledgements We thank Clare Venney, Mitch Dender, Calvin Kellendonk, Megan Mickle, Pauline Capelle, Nate Antoniolli, Jane Drown, and the staff at Yellow Island Aquaculture Ltd. for their contributions to fish husbandry and sample collection. We also thank three anonymous reviewers for their constructive comments that improved this manuscript. This work was supported by an NSERC Discovery grant to DDH and an NSERC post-graduate scholarship to KWW.

\section{Compliance with ethical standards}

Conflict of interest The authors declare that they have no competing interests. 


\section{References}

Agrawal AA (2001) Phenotypic plasticity in the interactions and evolution of species. Science 294:321-326

Artemov AV, Mugue NS, Rastorguev SM, Zhenilo S, Mazur AM, Tsygankova SV et al. (2017) Genome-wide DNA methylation profiling reveals epigenetic adaptation of stickleback to marine and freshwater conditions. Mol Biol Evol 34: 203-2213

Aubin-Horth N, Renn SCP (2009) Genomic reaction norms: using integrative biology to understand molecular mechanisms of phenotypic plasticity. Mol Ecol 18:3763-3780

Aykanat T, Bryden CA, Heath DD (2012) Sex-biased genetic component distribution among populations: additive genetic and maternal contributions to phenotypic differences among populations of Chinook salmon. J Evol Biol 25:682-690

Aykanat T, Heath JW, Dixon B, Heath DD (2012) Additive, nonadditive and maternal effects of cytokine transcription in response to immunostimulation with Vibrio vaccine in Chinook salmon (Oncorhynchus tshawytscha). Immunogenetics 64:691-703

Aykanat T, Thrower FP, Heath DD (2011) Rapid evolution of osmoregulatory function by modification of gene transcription in steelhead trout. Genetica 139:233-242

Bourguet D (1999) The evolution of dominance. Heredity 83:1-4

Dayan DI, Crawford DL, Oleksiak MF (2015) Phenotypic plasticity in gene expression contributes to divergence of locally adapted populations of Fundulus heteroclitus. Mol Ecol 24:3345-3359

de Jong G (2005) Evolution of phenotypic plasticity: patterns of plasticity and the emergence of ecotypes. New Phytol 166:101-118

Dietz TJ, Somero GN (1992) The threshold induction temperature of the $90-\mathrm{kDa}$ heat shock protein is subject to acclimatization in eurythermal goby fishes (genus Gillichthys). Proc Natl Acad Sci USA 89:3389-3393

Elphinstone MS, Hinten GN, Anderson MJ, Nock CJ (2003) An inexpensive and high-throughput procedure to extract and purify total genomic DNA for population studies. Mol Ecol Notes 3:317-320

Evans ML, Neff BD, Heath DD (2010) Quantitative genetic and translocation experiments reveal genotype-by-environment effects on juvenile life-history traits in two populations of Chinook salmon (Oncorhynchus tshawytscha). J Evol Biol 23:687-698

Ewing RD, Sheahan JE, Lewis MA, Palmisano AN (1998) Effects of rearing density and raceway conformation on growth, food conversion, and survival of Juvenile Spring Chinook salmon. Prog Fish Cult 60:167-178

Ghalambor CK, Hoke KL, Ruell EW, Fischer EK, Reznick DN, Hughes KA (2015) Non-adaptive plasticity potentiates rapid adaptive evolution of gene expression in nature. Nature 525:372-375

Ghalambor CK, McKay JK, Carroll SP, Reznick DN (2007) Adaptive versus non-adaptive phenotypic plasticity and the potential for contemporary adaptation in new environments. Funct Ecol 21:394-407

Gibson G, Weir B (2005) The quantitative genetics of transcription. Trends Genet 21:616-623

Gilad Y, Rifkin SA, Pritchard JK (2008) Revealing the architecture of gene regulation: the promise of eQTL studies. Trends Genet 24:408-415

Gotthard K, Nylin S (1995) Adaptive plasticity and plasticity as an adaptation: a selective review of plasticity in animal morphology and life history. Oikos 74:3-17

Greig C, Jacobson DP, Banks MA (2003) New tetranucleotide microsatellites for fine-scale discrimination among endangered
Chinook salmon (Oncorhynchus tshawytscha). Mol Ecol Notes 3:376-379

Halekoh U, Højsgaard S (2014) A kenward-roger approximation and parametric bootstrap methods for tests in linear mixed models the R package pbkrtest. J Stat Softw 59:1-32

Hori TS, Gamperl A, Booman M, Nash GW, Rise ML (2012) A moderate increase in ambient temperature modulates the Atlantic cod (Gadus morhua) spleen transcriptome response to intraperitoneal viral mimic injection. BMC Genomics 13:431

Jeffries KM, Hinch SG, Sierocinski T, Pavlidis P, Miller KM (2014) Transcriptomic responses to high water temperature in two species of Pacific salmon. Evol Appl 7:286-300

Kalinowski ST, Taper ML, Marshall TC (2007) Revising how the computer program cervus accommodates genotyping error increases success in paternity assignment. Mol Ecol 16:1099-1106

Kappeler L, Meaney MJ (2010) Epigenetics and parental effects. Bioessays 32:818-827

Karlen Y, McNair A, Perseguers S, Mazza C, Mermod N (2007) Statistical significance of quantitative PCR. BMC Bioinformatics 8:131

Kassahn KS, Crozier RH, Pörtner HO, Caley MJ (2009) Animal performance and stress: responses and tolerance limits at different levels of biological organisation. Biol Rev 84:277-292

Kenward MG, Roger JH (1997) Small sample inference for fixed effects from restricted maximum likelihood. Biometrics 53:983

Kihslinger RL, Nevitt GA (2006) Early rearing environment impacts cerebellar growth in juvenile salmon. J Exp Biol 209:504-509

Kim J, Gibson G (2010) Insights from GWAS into the quantitative genetics of transcription in humans. Genet Res 92:361-369

Komoroske LM, Connon RE, Jeffries KM, Fangue NA (2015) Linking transcriptional responses to organismal tolerance reveals mechanisms of thermal sensitivity in a mesothermal endangered fish. Mol Ecol 24:4960-4981

Lande R (2015) Evolution of phenotypic plasticity in colonizing species. Mol Ecol 24:2038-2045

Leder EH, McCairns RJS, Leinonen T, Cano JM, Viitaniemi HM, Nikinmaa $\mathrm{M}$ et al. (2015) The evolution and adaptive potential of transcriptional variation in sticklebacks - signatures of selection and widespread heritability. Mol Biol Evol 32:674-689

Ledón-Rettig CC, Pfennig DW, Chunco AJ, Dworkin I (2014) Cryptic genetic variation in natural populations: a predictive framework. Integr Comp Biol 54:783-793

Liu Y, Beyer A, Aebersold R (2016) On the dependency of cellular protein levels on mRNA Abundance. Cell 165:535-550

Lockwood BL, Somero GN (2011) Transcriptomic responses to salinity stress in invasive and native blue mussels (genus Mytilus). Mol Ecol 20:517-529

Logan CA, Somero GN (2011) Effects of thermal acclimation on transcriptional responses to acute heat stress in the eurythermal fish Gillichthys mirabilis (Cooper). AJP Regul Integr Comp Physiol 300:R1373-R1383

Lynch M, Walsh B (1998) Genetics and analysis of quantitative traits. Sinauer Associates, Sunderland

Mommsen TP, Vijayan MM, Moon TW (1999) Cortisol in teleosts: dynamics, mechanisms of action, and metabolic regulation. Rev Fish Biol Fish 9:211-268

Mousseau T, Fox C (1998) The adaptive significance of maternal effects. Trends Ecol Evol 13:403-407

Paaby AB, Rockman MV (2014) Cryptic genetic variation: evolution's hidden substrate. Nat Rev Genet 15:247-258

Perkins JR, Dawes JM, McMahon SB, Bennett DL, Orengo C, Kohl M (2012) ReadqPCR and NormqPCR: R packages for the reading, quality checking and normalisation of RT-qPCR quantification cycle $(\mathrm{Cq})$ data. BMC Genomics 13:296 
Pfennig DW, Wund Ma, Snell-Rood EC, Cruickshank T, Schlichting CD, Moczek AP (2010) Phenotypic plasticity's impacts on diversification and speciation. Trends Ecol Evol 25:459-467

Pigliucci M (2005) Evolution of phenotypic plasticity: Where are we going now? Trends Ecol Evol 20:481-486

Plaistow S, Benton T (2009) The influence of context-dependent maternal effects on population dynamics: an experimental test. Philos Trans R Soc B Biol Sci 364:1049-1058

Price TD, Qvarnstrom A, Irwin DE (2003) The role of phenotypic plasticity in driving genetic evolution. Proc R Soc B Biol Sci 270:1433-1440

R Core Team (2016) R: A language and environment for statistical computing. R Foundation for Statistical Computing, Vienna, Austria. https://www.R-project.org/

Ramakers C, Ruijter JM, Deprez RHL, Moorman AFM (2003) Assumption-free analysis of real-time polymerase chain reaction (PCR) data. Neurosci Lett 339:62-66

Richter K, Haslbeck M, Buchner J (2010) The heat shock response: life on the verge of death. Mol Cell 40:253-266

Scheiner S (1993) Genetics and evolution of phenotypic plasticity. Annu Rev Ecol Syst 24:35-68

Scheiner SM, Lyman RF (1989) The genetics of phenotypic plasticity I. Heritability. J Evol Biol 2:95-107

Schlichting CD, Smith H (2002) Phenotypic plasticity: linking molecular mechanisms with evolutionary outcomes. Evol Ecol 16:189-211

Taylor E (1991) A review of local adaptation in Salmonidac, with particular reference to Pacific and Atlantic salmon. Aquaculture 98:185-207

Tomalty KMH, Meek MH, Stephens MR, Rincon G, Fangue Na, May BP et al. (2015) Transcriptional response to acute thermal exposure in Juvenile Chinook salmon determined by RNAseq. G3 5:1335-1349

Tuomi JM, Voorbraak F, Jones DL, Ruijter JM (2010) Bias in the Cq value observed with hydrolysis probe based quantitative PCR can be corrected with the estimated PCR efficiency value. Methods 50:313-322

Vandesompele J, De Preter K, Pattyn F, Poppe B, Van Roy N, De Paepe A et al. (2002) Accurate normalization of real-time quantitative RT-PCR data by geometric averaging of multiple internal control genes. Genome Biol 3:research0034.1-research0034.11

Via S, Lande R (1985) Genotype-environment interaction and the evolution of phenotypic plasticity. Evolution 39:505-522

Wedemeyer GA (1976) Physiological response of juvenile Coho Salmon (Oncorhynchus kisutch) and Rainbow Trout (Salmo gairdneri) to handling and crowding stress in intensive fish culture. J Fish Res Board Can 33:2699-2702

Wendelaar Bonga SE (1997) The stress response in fish. Physiol Rev 77:591-625

Whitehead A, Crawford DL (2006) Neutral and adaptive variation in gene expression. Proc Natl Acad Sci USA 103:5425-5430

Williamson KS, Cordes JF, May B (2002) Characterization of microsatellite loci in Chinook salmon (Oncorhynchus tshawytscha) and cross-species amplification in other salmonids. Mol Ecol Notes 2:17-19

Wiseman S, Osachoff H, Bassett E, Malhotra J, Bruno J, VanAggelen $\mathrm{G}$ et al. (2007) Gene expression pattern in the liver during recovery from an acute stressor in rainbow trout. Comp Biochem Physiol Part D Genomics Proteomics 2:234-244

Wittkopp PJ, Kalay G (2012) Cis-regulatory elements: molecular mechanisms and evolutionary processes underlying divergence. Nat Rev Genet 13:59-69 